\title{
SEM ELEIÇÃO DIRETA PARA DIRETOR (A) DE ESCOLA NÃO HÁ GESTÃO DEMOCRÁTICA? - UM ESTUDO DOS MUNICÍPIOS DA SERRA CATARINENSE
}

\author{
NO DIRECT ELECTION FOR SCHOOL DIRECTORS IS THERE NO \\ DEMOCRATIC MANAGEMENT? - A STUDY OF THE \\ MUNICIPALITIES OF SERRA CATARINENSE
}

\author{
¿QUÉ ES LA ELECCIÓN DIRECTA PARA DIRECTOR (A) DE \\ ESCUELA NO HAY GESTIÓN DEMOCRÁTICA? - UN ESTUDIO DE \\ LOS MUNICIPIOS DE LA SIERRA CATARINENSE
}

\author{
Carlos Eduardo Moreira' Jaime José Zitkoski ${ }^{2}$
}

\begin{abstract}
RESUMO
Este texto discute um conjunto de implicações do impedimento legal para a eleição direta de diretor da escola pública pela comunidade escolar para a gestão democrática dos sistemas municipais de ensino na Serra Catarinense. Reúne os principais dispositivos legais que garantem a efetivação de mecanismos e procedimentos da gestão democrática, considerando os resultados de pesquisa realizada no período de 2012 a 2016 e reflexões de programa regional em dezessete municípios da Serra Catarinense. Para a consolidação da gestão democrática, o texto reúne os elementos básicos da Teoria da Ação Dialógica de Paulo Freire, para defender que a mudança nas relações sociais nos sistemas de ensino devem ser estruturadas por meio de práticas dialógicas, que não são conciliáveis com o modelo gerencialista de regulação de políticas educacionais de organizações privadas. Por último, o texto analisa os principais desafios e possibilidade de efetivação da gestão democrática como um duplo movimento: buscar estratégias para efetivar institucionalidades e procedimentos para a gestão democrática, consagrados na legislação atual, e reorganizar o processo de formação continuada e inicial dos educadores e educadoras para assumirem a condição de sujeitos na construção democrática da política de Educação Básica.
\end{abstract}

PALAVRAS-CHAVE: Paulo Freire. Gestão Democrática. Projeto Democrático-Participativo.

\section{ABSTRACT}

This text discusses a set of implications of the legal impediment for the direct election of public school director by the school community for the democratic management of the municipal education systems in the Serra Catarinense. It brings together the main legal mechanisms that guarantee the implementation of mechanisms and procedures of democratic management, considering the results of research carried out in the period from 2012 to 2016 and reflections of a regional program in seventeen municipalities of Serra Catarinense. For the consolidation of democratic management, the text brings together the basic elements of Paulo Freire's Theory of Dialogical Action, to defend that the change in social relations in education systems should be structured through dialogic practices that are not reconcilable with the model educational

\footnotetext{
${ }^{1}$ Pós Doutorando na UFRGS

${ }^{2}$ Doutorado em Educação pela UFRGS; DEBAS-Faced-UFRGS.
} 
policy regulation of private organizations. Finally, the text analyzes the main challenges and possibility of effective democratic management as a double movement: seek strategies to implement institutions and procedures for democratic management, enshrined in current legislation, and reorganize the process of continuous and initial training of educators and educators to assume the condition of subjects in the democratic construction of the Basic Education policy.

KEYWORDS: Paulo Freire. Democratic management. Democratic-Participatory Project.

\section{RESUMEN}

Este texto discute un conjunto de implicaciones del impedimento legal para la elección directa de director de la escuela pública por la comunidad escolar para la gestión democrática de los sistemas municipales de enseñanza en la Sierra Catarinense. Reúne los principales dispositivos legales que garantizan la efectividad de mecanismos y procedimientos de la gestión democrática, considerando los resultados de investigación realizada en el período de 2012 a 2016 y reflexiones de programa regional en diecisiete municipios de Serra Catarinense. Para la consolidación de la gestión democrática, el texto reúne los elementos básicos de la Teoría de la Acción Dialógica de Paulo Freire, para defender que el cambio en las relaciones sociales en los sistemas de enseñanza debe ser estructurado por medio de prácticas dialógicas, que no son conciliables con el modelo gerencialista de regulación de políticas educativas de organizaciones privadas. Por último, el texto analiza los principales desafíos y posibilidad de efectividad de la gestión democrática como un doble movimiento: buscar estrategias para efectivizar institucionalidades y procedimientos para la gestión democrática, consagrados en la legislación actual, y reorganizar el proceso de formación continuada e inicial de los educadores y, educadoras para asumir la condición de sujetos en la construcción democrática de la política de Educación Básica.

PALABRAS CLAVE: Paulo Freire. Gestión Democrática. Proyecto Democrático-Participativo.

\section{CONSIDERAÇÕES INICIAIS}

No atual contexto de ruptura histórico-institucional com o Golpe de 2016, no Brasil, o afastamento do Governo Federal de uma presidente eleita democraticamente, favoreceu o enaltecimento do centralismo autoritário do Poder Executivo e a prevalência do Poder Judiciário em detrimento da discussão democrática entre "diferentes" e "antagônicos", o que pode potencializar o esvaziamento de institucionalidades democráticas com riscos efetivos para a continuidade de discussão e concertação da política educacional municipal, como já está sendo delineado pelos pronunciamentos do Presidente eleito. Um fato marcante é a restrição pública às ideias de Paulo Freire por este novo Governo Federal, evidenciando mudanças para a convivência da diversidade de ideias e projetos políticos, uma das principais conquistas na política brasileira dos últimos trinta anos. 


\section{CIÊNCIAS HUMANAS}

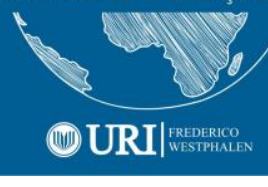

Mesmo assim, as conquistas celebradas a partir da consignação da gestão educacional democrática como valor e princípio no texto constitucional de 1988 definiram que as políticas educacionais devem ser elaboradas, controladas e avaliadas com a participação efetiva da comunidade escolar, dos agentes do Estado e de representantes da sociedade como um todo.

Como desdobramento dessas conquistas, a legislação infraconstitucional no ensino público consagrou a gestão democrática e determinou aos municípios brasileiros que definissem para os seus sistemas de ensino como se daria a sua efetivação. Para isso, universidades, movimentos sociais, sindicatos e as próprias secretarias municipais de educação não só buscaram debater e atualizar a legislação de ensino, mas organizaram inúmeras atividades de formação para que a cultura democrática superasse o formalismo legal e o transformasse em práxis social, como aconteceu em inúmeros municípios que reinventaram o pensamento de Paulo Freire e refletiram criticamente sobre o quanto a democratização dos sistemas de ensino e das relações sociais contribuiriam para a conquista da qualidade social da Educação Básica.

Nesse trabalho de formação para a democracia, em municípios brasileiros, um dos maiores desafios foi desenvolver um processo formativo de pessoas para que pudessem "pronunciar o Mundo", afirmando o que esperam da educação escolar e assumindo o compromisso de participar do trabalho coletivo em espaços públicos. Uma construção que tem ritmo próprio que confronta-se com os determinantes da burocracia estatal com as exigências de procedimentos rígidos e resultados a curto prazo, mensurados em números e anotados em relatórios longos e incompreensíveis, além de avaliações impositivas de técnicos dos órgãos de controle do Estado.

O processo educativo coletivo, como coordenou o educador Paulo Freire na cidade de São Paulo, é tenso, complexo e repleto de resistências daqueles que querem manter o "velho" e outros que temem a "possibilidade do novo". Ou seja, depende de como as pessoas respondem às diferentes formas de problematização da realidade educacional e como elaboram as suas conclusões. Uma dinâmica extremamente provocativa quando o diálogo é intenso e radical entre os sujeitos envolvidos, como 


\section{CIÊNCIAS HUMANAS}

Freire experimentou com a criação dos conselhos gestores e o desenvolvimento de atividades de formação continuada para educadores e educadoras da rede pública, superando o reducionismo pedagógico que separa o trabalho pedagógico escolar das dimensões históricas, econômicas, políticas e sociais (FREIRE, 1991).

A beleza desse movimento formativo está em inúmeras aberturas para diálogos problematizadores e alternativas ao fazer pedagógico, bem como novas conformações de espaços públicos e momentos que vão surgindo da necessidade de resolver desafios que estão presentes no trabalho educativo, em função de reivindicações expressas pela comunidade escolar, em especial, pelos educadores e pelas educadoras que lutam pela melhoria das condições do trabalho escolar.

Desses ritmos, momentos e novos espaços públicos, no Brasil, foi produzida uma legislação de ensino que consagrou a gestão democrática como imprescindível para a Educação Básica. Definições que se originaram de eventos e produções acadêmicas, das lutas dos setores progressistas para o estabelecimento da gestão democrática com novas institucionalidades e procedimentos que estão anotados no inciso VI do artigo 206, da Constituição Federal de 1988 (CF/88) (BRASIL, 2014) e no inciso VIII do artigo $3^{\circ}$, da Lei de Diretrizes e Bases de 1996 (LDB/96) (BRASIL, 2018a).

O avanço constitucional, o aperfeiçoamento da legislação municipal e a realização de processos formativos contribuíram para mudanças nas práticas de gestão escolares, proporcionando um amplo debate sobre o tema e garantindo condições necessárias para a criação de experiências exemplares em vários municípios brasileiros. Experiências marcadas por inúmeras tensões entre a cultura democrática e a chamada cultura política centralizadora e autoritária, que não tem reconhecido o outro como capaz de participar dos rumos da educação pública e da gestão das políticas públicas. Em geral, essa cultura tem como principais características a convivência com a forte hierarquização social e o não compartilhamento do poder de decidir dos governantes com a sociedade, presentes na maioria das administrações dos municípios brasileiros.

Nesses municípios, em 2017 e 2018, em encontros com pedagogas das secretarias municipais de educação, diretores (as), educadoras e educadores de escolas dos 


\section{CIÊNCIAS HUMANAS}

REVISTA DO PROGRAMA DE PÓS-GRADUAÇ̄O EM EDUCAÇ̄OA

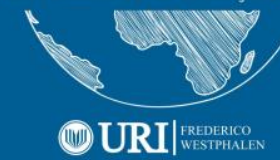

municípios que participam do Programa de Educação Municipal do Consórcio Público Serra Catarinense (CISAMA) ${ }^{3}$, houve um consenso entre eles de que não havia gestão democrática nos sistemas de ensino. Esse posicionamento demonstrou incerteza e descrédito, inclusive, sobre o valor do tema no atual contexto de ruptura históricoinstitucional no país, com a tendência a expansão de governos centralizadores e autoritários e a disseminação da máxima que dialogar é perda de tempo e do tido popular "manda quem pode e obedece que tem juízo". A constatação também é preocupante para aqueles que lutaram pela democratização da Educação Básica e acreditaram (e ainda acreditam) que ela é um fator preponderante para a construção de uma educação com qualidade social, capaz de formar cidadãs e cidadãos críticos, criativos e comprometidos com uma sociedade democrática, fraterna e menos desigual.

A afirmação de que não havia uma gestão democrática da educação pública municipal em função da impossibilidade da eleição direta do (a) diretor (a) pela comunidade escolar tem a ver com o posicionamento dos tribunais de justiça e do próprio Supremo Tribunal Federal (STF), há pelo menos dez anos, cujo principal argumento é que o cargo de diretor (a) de escolas é um cargo em comissão, cujo provimento pertenceria à esfera discricionária do chefe do Poder Executivo ${ }^{4}$. Um argumento que vinculou, nos termos das leis municipais, somente à exigência de critérios técnicos e formativos para o exercício do cargo, tanto pela formação inicial na área da educação como pelo pertencimento ao quadro do funcionalismo público municipal, mas que a escolha deveria ser de livre nomeação pelo prefeito.

Cabe ressaltar que essa prerrogativa, na maioria das vezes, tem sido utilizada como forma de favorecimento de profissionais que possuem vínculos partidários e

\footnotetext{
${ }^{3}$ O CISAMA é um consórcio multi-finalitário que surgiu em 2009 na Serra catarinense, ampliando o seu campo de atuação com a criação do Programa, em 2017, atingindo cerca de 13.700 (treze mil e setecentos) educandos, 258 (duzentos e cinquenta e oito) diretores de escolas públicas municipais e 1.500 (mil e quinhentos) educadores e educadoras.

${ }^{4}$ Em decisão tomada no julgamento da Ação Direta de Inconstitucionalidade (ADI) 2997, ajuizada no STF pelo Partido Social Cristão (PSC) contra os dispositivos da Constituição Estadual do Rio de Janeiro que garantiam a eleição direta do (a) diretor (a) pela comunidade escolar, o relator do processo, Ministro Cezar Peluso, lembrou que o tema já foi amplamente discutido e pacificado pela Corte, e votou pela procedência da ação, entendimento que foi seguido à unanimidade pelos demais Ministros presentes à sessão do dia 12 de agosto de 2009.

\begin{tabular}{l|l|l} 
Rev. Ciências Humanas & Frederico Westphalen, RS & Jan./abr. 2019
\end{tabular}




\section{CIÊNCIAS HUMANAS}

REVISTA DO PROGRAMA DE PÓS-GRADUAÇÃO EM EDUCAÇĀO

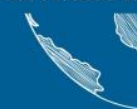

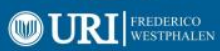

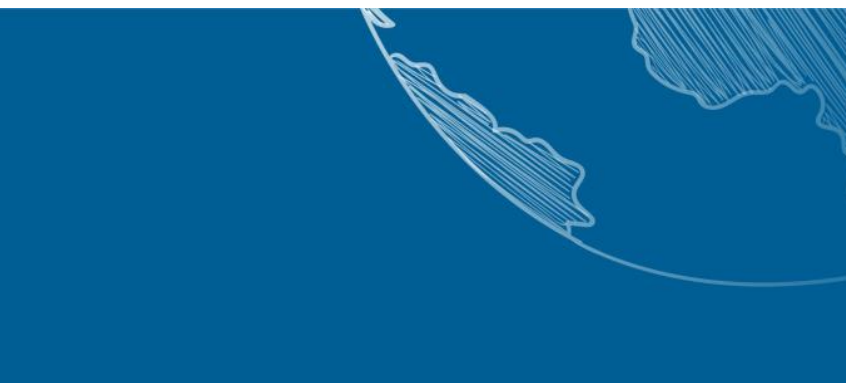

relações pessoais com os governantes municipais. Uma forma de escolha que também envolveu outros profissionais para atuar nas secretarias municipais de educação enquanto uma prática de clientelismo educacional. Nesse processo, criaram-se, também, situações de conflito após a escolha de diretores (as) que, além de não terem o apoio da comunidade escolar, demonstraram não possuir a qualificação técnica necessária para o exercício das funções de direção e suporte técnico às escolas públicas municipais, previstas em leis municipais e no projeto político-pedagógico das escolas (MOREIRA, 2016).

Associada a essa imposição, a judicionalização da Educação Básica tem-se caracterizado, em Santa Catarina, como a interferência direta dos órgãos de controle institucional do Estado, realizando inúmeras ameaças aos secretários (as) municipais de e profissionais da educação em eventos coletivos, bem como realizando visitas repentinas aos municípios, o que tem reforçado o caráter normativo da educação escolar, sendo materializado no Acordo de Cooperação Técnica celebrado entre a Associação dos Membros dos Tribunais de Contas do Brasil (ATRICON), o Instituto Rio Branco (IRB) e o FNDE/MEC, em 2016 ${ }^{5}$ A partir desse acordo, o Tribunal de Contas do Estado de Santa Catarina (TCE/SC) realizou dois fóruns de educação, um ciclo de estudos regionalizado com representantes dos municípios e um evento de capacitação com conselheiros municipais, em 2018, para propor o aperfeiçoamento do controle social na efetivação de metas e estratégias dos planos de educação, com a inclusão dessas na Lei Orçamentária Anual (LOA) de cada município.

Dessa forma, este texto procura responder ao seguinte questionamento: até que ponto a impossibilidade legal de realização da eleição direta para o diretor (a) pela comunidade escolar limita a efetivação da gestão democrática na escola pública municipal, considerando a existência de institucionalidades e procedimentos que

\footnotetext{
${ }^{5}$ Nos termos do Acordo de Cooperação Técnica, de uma forma geral, coube ao FNDE/MEC fornecer dados atualizados e à ATRICON e ao IRB a responsabilidade de atuar para efetivação das metas e das estratégias dos planos de educação, conforme as leis específicas. Disponível em: http://www.atricon.org.br/wpcontent/uploads/2013/07/Acordo Cooperacao Tecnica Rede Informacao Estrategicas.pdf. Acesso em: 25/09/2018
} 
garantem a participação da comunidade escolar na elaboração e no controle da política de educação municipal?

Para responder a esse questionamento, o texto está organizado em três momentos distintos e complementares: primeiro, são apresentadas as principais mudanças legais e reflexões que afirmaram a gestão democrática da educação municipal; segundo, discutese a efetividade das principais institucionalidades e da adoção de procedimentos atuais para a participação social na escola pública, e terceiro, são apresentadas e discutidas um conjunto de implicações sobre os desafios e as possibilidades de efetivação da gestão democrática para além da eleição direta do (a) diretor (a) da escola pública municipal.

\section{O CONTEXTO DE AVANÇOS NA LEGISLAÇÃO E NO DEBATE DO CAMPO TEÓRICO SOBRE O TEMÁ GESTÃO DEMOÇRÁTICA}

A proposição de eleição direta para diretor (a) de escola pela comunidade escolar foi uma das principais conquistas na história da educação brasileira, consagrada também no texto do I Plano Nacional de Educação, em 2001, nos Objetivos e Metas do item "Financiamento e Gestão" (BRASIL, 2001). Neste I Plano foram reunidas garantias efetivas para a gestão democrática dos sistemas municipais de ensino, destacando-se: o regime de colaboração entre redes e sistemas de ensino, a criação de conselhos municipais de educação, a autonomia administrativa e pedagógica das escolas e a ampliação da autonomia financeira por meio do repasse de recursos para pequenas despesas de manutenção e execução de sua proposta pedagógica.

Mas se na gestão de um sistema municipal de ensino não é possível a eleição direta para diretor (a) de escola pela comunidade escolar, então não existiria uma gestão democrática nesse sistema? Enfim, o que é uma gestão democrática da educação?

A gestão, ou melhor, a ger em latim, que significa fazer brotar, germinar e fazer nascer, implica a possibilidade de um ou mais interlocutores, por meio do diálogo, decidir responsabilidades e agir em busca dos mesmos objetivos. Dessa forma, a gestão democrática é um aprendizado em relação que resulta da implantação de um conjunto de

\begin{tabular}{l|l|l|}
\hline Rev. Ciências Humanas & Frederico Westphalen, RS & Jan./abr. 2019 \\
\hline
\end{tabular}

\begin{tabular}{l|l} 
Recebido em: 31/03/2019 & Aceito em: 30/04/2019
\end{tabular}

Pg. $160-177$ 


\section{CIÊNCIAS HUMANAS}

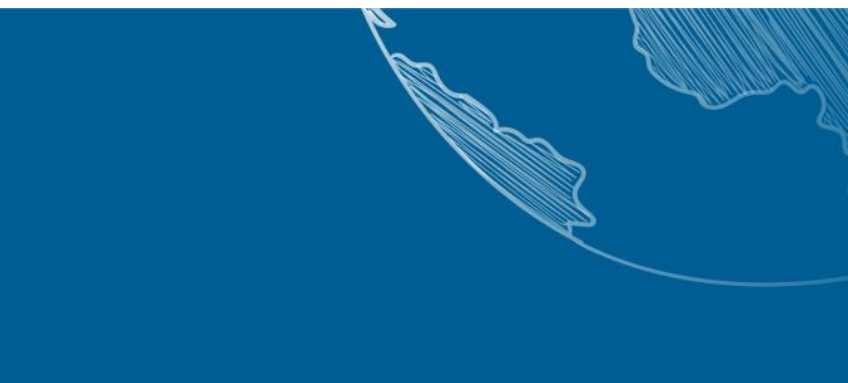

práticas dialógicas criadas articuladamente em espaços pedagógicos coletivos, formais e informais, que precisam ser ocupados com a participação de sujeitos na condução de ações de trabalho e dispostos a assumir a complexidade da indeterminação das decisões em práticas democráticas.

$\mathrm{Na}$ esteira da tradição de experiências exemplares de projetos educacionais democráticos em estados e municípios brasileiros, nos anos 90 e na primeira década do século XXI, houve o aproveitamento da descentralização da política de Educação Básica para que os municípios implementassem o seu projeto educacional. Cabe ressaltar que estados e municípios tiveram a iniciativa de buscar os meios necessários para viabilizar essa formação para a democracia por meio de convênios, parcerias ou termos de cooperação com universidades, ONGs, assessoria de educadores populares, apoio de associações e sindicatos de educadores (as), formação de grupos de trabalho com a participação da comunidade escolar e representantes da sociedade, desenvolvimento de metodologias participativas de planejamento entre outros.

Outro traço significativo dessas experiências foi a utilização dos referenciais freireanos para a construção democrática de relações pedagógicas, institucionalidade e adoção de procedimentos da democracia participativa no campo das políticas educacionais, com a criação e ampliação dos canais de participação e, principalmente, o trabalho de formação continuada para educadores e educadoras. Destacavam-se a postura educativa dos agentes do Estado, nessas experiências, e a utopia de criar espaços de negociação de conflitos mesmo existindo os chamados riscos da indeterminação do processo democrático, do não saber o que será definido, a princípio, antes da finalização do debate coletivo. Ou seja, voltou-se para o reconhecido do outro como um sujeito de direitos que precisava expressar a maneira como compreendia e experimentava a sua condição social e se colocava diante do projeto de educação em curso (FREIRE, 1991). O que também provocou um grande esforço de superação de inúmeras permanências do Estado autoritário e resistências de membros da comunidade escolar para a constituição 


\section{CIÊNCIAS HUMANAS}

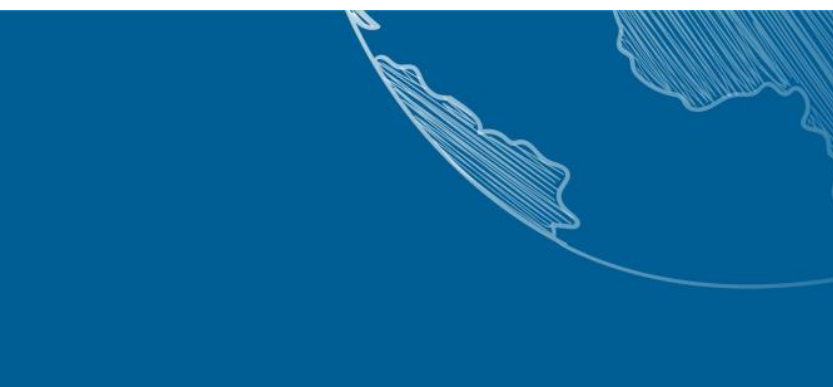

de uma cultura democrática no ambiente escolar por meio do "aprendizado em relação" (MOREIRA, 2016).

As práticas dialógicas precisam estar presentes, principalmente, na relação educador-educando e se prolongarem na gestão da escola e da própria política educacional como um todo, sendo a expressão do caminho pedagógico que leva à reflexão da própria condição humana no Mundo (FREIRE, 1987). Nessa perspectiva, o dialogar se revela em uma ação efetiva de pessoas para construírem uma relação de confiança recíproca, incorporando sugestões e críticas por meio de relações intersubjetivas que favorecem a ressignificação do fazer pedagógico enquanto uma prática coletiva que é promotora do aprendizado de conhecimentos e práticas sociais. Como afirmou Kosik (1985, p. 206): “Conhecemos o Mundo, as coisas, os processos somente na medida em que os 'criamos', isto é, na medida em que os reproduzimos espiritualmente e intelectualmente".

É evidente que a escolha de diretor tem importância imensa e não pode ser tratada como algo sem valor, algo menor. Em muitas escolas municipais da Serra Catarinense, pelo fato do (a) diretor (a) ter um vínculo político-partidário com a Secretaria de Educação e não ter sido escolhido (a) pela comunidade traz inúmeros conflitos que podem levar a intervenção direta do (a) secretário (a) de educação ou do próprio prefeito. $\mathrm{Na}$ verdade, a escolha pela comunidade poderia contribuir mais rapidamente para que a gestão democrática fosse configurada em uma prática cotidiana nas relações sociais dos ambientes educativos. Mas devemos ressaltar que existem várias conquistas que também foram definidas na legislação de ensino e incorporadas ao processo de gestão escolar, na últimas duas décadas, que garantiram institucionalidades e procedimentos que foram identificados com a chamada Democracia Participativa de Alta Intensidade (SANTOS, 2002).

Na Democracia Participativa de Alta Intensidade, a participação qualificada em espaços públicos não se esgotaria em um momento específico, no processo de escolha do (da) diretor (a) de escola, por exemplo. Mas na constituição de uma "cultura de 


\section{CIÊNCIAS HUMANAS}

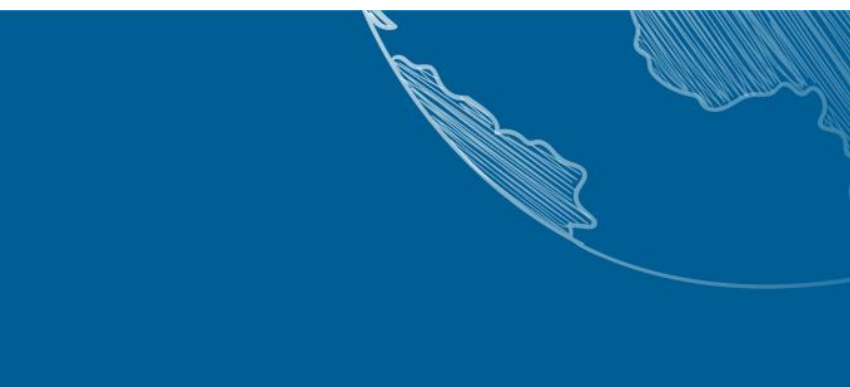

participação e solidariedade" como um aprendizado em relação que, segundo esse autor, "é uma cultura contracorrente nas sociedades em que a domina o individualismo possessivo [...]" (p. 120), na qual não existe a tutela de pessoas eleitas ou lideranças centralizadoras. A participação qualificada exigiria comprometimento dos participantes para um projeto coletivo, visando a melhoria das condições de vida de todos, por meio de uma formação voltada para o empoderamento dos sujeitos participantes a partir de interações sociais em que há o processo de conscientização, oportunizando a descoberta de "brechas e ideologias" e a conquista de poder para à liberdade e à libertação" (GUARESCHI, 2008).

Nessa perspectiva, como também nos colocou Paulo Freire (1994), mais importante do que conquistar o poder a partir de eleições democráticas é fundamental a reinvenção do poder. Pois a lógica do poder numa democracia meramente representativa poderá levar a manutenção de uma estrutura centralizada e, portanto, adversa ao processo participativo, dialógico e incentivador da inclusão dos diferentes sujeitos sociais. A reinvenção do poder requer, fundamentalmente, uma pedagogia da política. Ou seja, as lideranças de toda e qualquer instância de poder precisam estar abertas às vozes dos liderados. Uma vez que em um processo radicalmente democrático cada um e cada uma tem o direito de dizer a sua palavra e se expor às críticas dos demais. Não existe alguém que é "dono da verdade", pois o olhar para a realidade depende de cada contexto e experiências marcantes de cada ser humano em seu movimento na história.

Por tais razões, a substantividade democrática no exercício da prática política de que nos falou Freire (1994) requer a prática do diálogo, da busca do entendimento como princípio, que precisa estar acima de outros mecanismos e/ou estratégias da luta política para a transformação/humanização do mundo.

Essa reinvenção do poder consiste em transformação e rupturas com a cultura autoritária e o formalismo legal da democracia representativa, ou da "pura conquista" do poder. Se ocorrer a conquista do poder pelas classes populares e não se transformarem as estruturas, o poder institucionalizado e a própria cultura da sociedade, então apenas se inverterão os polos e a opressão continuará. Então, o desafio da construção democrática 


\section{CIÊNCIAS HUMANAS}

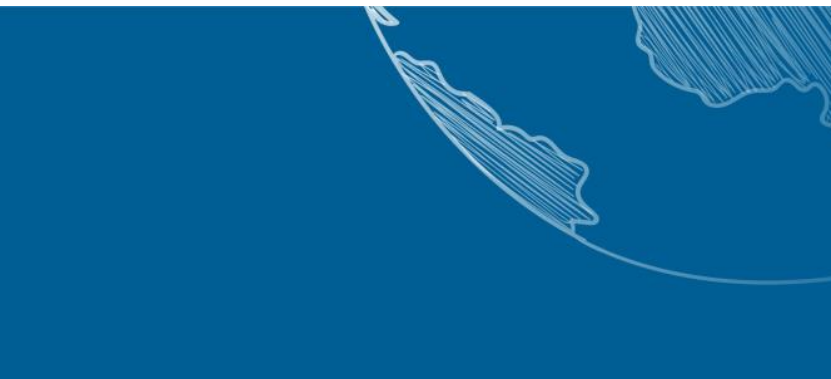

da sociedade, por isso mesmo, mais igualitária e justa, implica transcender a cultura política das sociedades burguesas liberais, expressas no modelo da democracia meramente representativa, para reinventar as relações de poder entre liderança e liderados (político-povo) com novas práticas de construção da democracia sem fim, conforme apontou também Santos (2002).

Para essa democracia sem fim, considerando os avanços nos textos legais, a garantia de uma gestão democrática na Educação Básica e sua reafirmação no artigo 14 da LDB/96 (BRASIL, 2018a), ampliou-se os espaços de participação dos diversos segmentos da sociedade na tomada de decisões acerca das políticas para a Educação Básica. Esse princípio também foi estendido aos sistemas de ensino, conforme estabeleceu o artigo 15 dessa Lei: "Os sistemas de ensino assegurarão às unidades escolares públicas de educação básica que os integra progressivos graus de autonomia pedagógica, administrativa e de gestão financeira, observando as normas gerais do direito financeiro público". Além da Lei Maior da Educação Básica, a Lei Federal n. 13.005/2014 (BRASIL, 2018b), que criou o II Plano Nacional de Educação, determinou que:

Os Estados, o Distrito Federal e os Municípios deverão aprovar leis específicas para os seus sistemas de ensino, disciplinando a gestão democrática da educação pública nos respectivos âmbitos de atuação, no prazo de 2 (dois) anos contado da publicação desta Lei, adequando, quando for o caso, a legislação local já adotada com essa finalidade.

Entretanto, nos municípios da Serra Catarinense, até março de 2019, não foi aprovada a lei específica da gestão democrática do sistema de ensino, apesar de constar no texto da lei de criação do sistema de ensino desses municípios, do plano de educação e dos conselhos de educação, indicando institucionalidades e procedimentos que conformam práticas de gestão democrática, tais como: constituição de fórum permanente de educação; realização de conferência municipal de educação; criação e implementação de conselho escolar, conselhos de educação, comissões de monitoramento; implementação do plano de carreira e do plano municipal de educação; organização do grêmio estudantil e elaboração coletiva do projeto político-pedagógico e do plano municipal de educação. Com isso, essas institucionalidades e procedimentos constituíram 


\section{CIÊNCIAS HUMANAS}

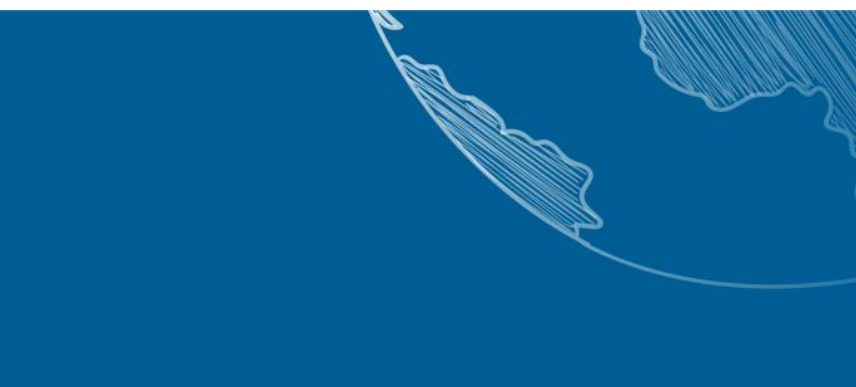

garantidas essenciais para a representação e participação da comunidade escolar e de diferentes segmentos sociais, indicados ou eleitos pelos seus pares, para que pudessem apresentar e defender demandas e interesses coletivos.

É importante destacar que essas institucionalidades e procedimentos apresentam relações entre si e não são de conhecimento da maioria da comunidade escolar: primeiro, o fórum municipal permanente da educação, que tem a finalidade de monitorar e avaliar a implementação da política pública de educação, no âmbito do município, coordena a coordenação da conferência municipal de educação, especialmente, na avaliação do plano municipal de educação; segundo, a conferência municipal de educação, espaço de debate, mobilização e formulação de políticas educacionais municipais, tem como base o plano de educação de cada município; terceiro, os conselhos de educação, órgãos colegiados de natureza pública, integrantes da estrutura administrativa da Prefeitura, com funções consultiva, propositiva, mobilizadora, deliberativa, normativa e fiscalizadora estão voltados para a efetivação do controle social e da gestão do sistema de ensino; quarto, o conselho escolar, órgão colegiado de natureza pública, formado por representantes da comunidade escolar, cuja principal finalidade é participar da gestão escolar, assegura a regularidade, a transparência e a efetividade dos atos praticados pela direção escolar, e por último, a Associação de Pais e Professores (APP), associação civil de natureza privada, sem fins lucrativos, de participação voluntária, tem como principal objetivo promover a integração entre escolas públicas e sociedade em geral, colaborando de forma complementar ou auxiliar aos atos e procedimentos praticados na gestão escolar.

Essas conquistas formais, consagradas em leis municipais e federais, não foram assumidas integralmente pelos (as) secretários (as) de educação, diretores (as) e comunidade escolar como um todo, conforme foi possível constatar por meio de pesquisa em outra região de Santa Catarina (MOREIRA, 2016) e durante o trabalho do Programa Educação Municipal do Consórcio Público Intermunicipal Serra Catarinense (CISAMA), no período de 2017 a 2018.

A efetividade dessas institucionalidades e procedimentos da gestão democrática envolve variáveis que são confrontadas pelo ethos político centralizador e autoritário da 


\section{CIÊNCIAS HUMANAS}

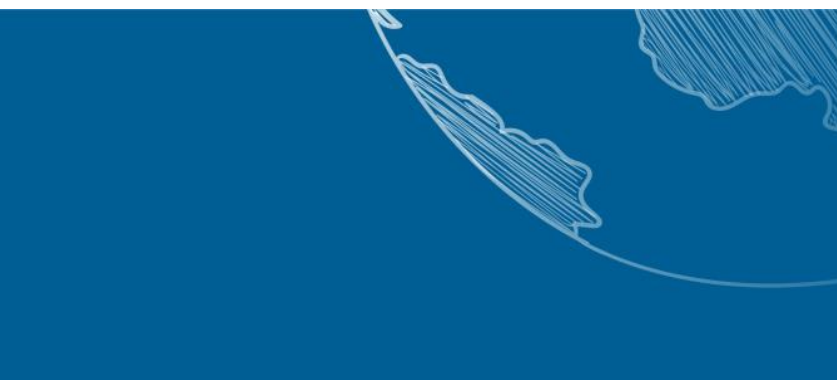

gestão pública, em cada contexto específico, o que tem dificultado o desenvolvimento de atividades formativas e a implementação desses com a participação da comunidade escolar.

\section{EFETIVIDADE DAS INSTITUCIONALIDADES E DOS PROCEDIMENTOS}

O principal desafio para a gestão democrática da Educação Básica tem a ver com a efetividade das institucionalidades e dos procedimentos já consagrados em Lei, garantidores da participação da comunidade escolar na política educacional, o que implicaria ser devidamente conhecidos para serem praticados e aperfeiçoados.

Em relação às principais institucionalidades de mobilização e participação social, conferência municipal de educação e fórum permanente de educação, no primeiro semestre de 2018, houve sutilmente o esvaziamento político dessas institucionalidades sob a orientação de técnicos (as) da Secretaria de Articulação com os Sistemas de Ensino (SASE) do Ministério da Educação (MEC), em comum acordo com a Secretaria de Estado da Educação de Santa Catarina, para que a conferência municipal de educação fosse realizada de forma aligeirada e não precisasse da constituição do fórum para a organização e coordenação da conferência, mas de uma pequena comissão sem a representatividade necessária da sociedade como um todo. Nesse esvaziamento, a maior parte da sociedade não pôde participar nem acompanhou os eventos municipais e regionais, que reuniriam contribuições para o aperfeiçoamento da política educacional do país. Já em relação aos conselhos municipais de educação, a maioria deles é prefeiturizado e têm realizado reuniões em função de demandas da Prefeitura e não para consolidar o controle social e fortalecer a transparência social (MOREIRA, 2018).

É importante destacar que a experiência política da comunidade escolar tem sido um impedimento para efetivar a implantação das institucionalidades e da adoção de procedimentos de gestão democrática, destacando-se a fragilidade na formação dos educadores e educadoras das escolas públicas municipais quanto aos temas relacionados 


\section{CIÊNCIAS HUMANAS}

mais diretamente à política educacional. Em geral, segundo afirmações dos próprios educadores e educadoras da Serra Catarinense, a formação inicial tem dado ênfase aos aspectos pedagógicos do trabalho docente, com o direcionamento do trabalho escolar para a preparação ao mercado de trabalho, separando os conteúdos escolares das experiências cotidianas dos sujeitos sociais, como afirmou Freire (2000), e tornando o fazer docente uma prática aparentemente neutra e despossuída de historicidade e intencionalidade.

Outro fato significativo tem sido a transferência de responsabilidade da comunidade escolar para o (a) diretor (a) e o (a) secretário (a) de educação na implementação da gestão democrática, como se fosse uma decisão exclusivamente deles (as), e a comunidade escolar não tivesse o direito de participar da gestão da escola e do sistema de ensino como um todo. Neste aspecto, cabe ressaltar que esse quadro se repete em outras políticas públicas da maioria dos municípios da Serra Catarinense.

Nessa incerteza ou ausência de uma defesa contundente da gestão educacional democrática pela comunidade escolar, especialmente, pelos pais, mães ou responsáveis, pelas educadoras e pelos educadores das escolas municipais, tem possibilitado, ainda mais, o crescimento de intervenções do gerencialismo educacional de organizações privadas nos sistemas de ensino, em processos de recriação conservadora e pragmática, reduzindo a descentralização democrática e a participação social a "técnicas de gestão aparentemente eficazes" com vista à racionalização e otimização dos sistemas educativos (LIMA, 2009).

No gerencialismo educacional, as organizações privadas têm oferecido cursos de formação para educadores (as) e diretores (as) com a utilização das chamadas pedagogias ativas e ferramentas de gestão de empresas privadas para os sistemas públicos de ensino. Essas intervenções podem ser consideradas como investimentos, ao mesmo tempo que são viáveis do ponto de vista financeiro em função da renúncia fiscal, com o abatimento no imposto de renda das empresas dos recursos gastos com material e pessoal em fundações e institutos privados, garantindo a coordenação ou intervenção nas políticas educacionais, além da contratação de profissionais da educação para "venderem" pacotes 


\section{CIÊNCIAS HUMANAS}

REVISTA DO PROGRAMA DE PÓS-GRADUAÇÃO EM EDUCAÇĀO

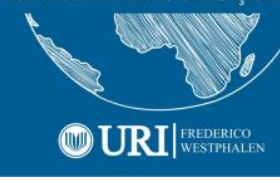

de trabalho às prefeituras, obrigando educadores e educadoras dos municípios a assumirem projetos e práticas que não condizem com as suas convicções e estão voltados para contribuir na construção do Projeto Político Neoliberal no país.

\section{PALAVRAS FINAIS}

Os principais desafios e possibilidades para a efetivação da gestão democrática, nos sistemas de ensino, fazem parte de um processo mais amplo de luta para a consolidação da democratização das políticas públicas e a conformação de uma cidadania ativa no país. É uma verdadeira disputa pela gestão da política educacional, uma vez que ela pode assumir um caráter transformador, contribuindo diretamente para o empoderamento das classes populares e a conquista da qualidade social da educação, ou reforçando a concepção de Educação Bancária e a submissão da educação escolar aos interesses e às demandas do mercado e dos setores conservadores da sociedade.

Em termos de desafios, é fundamental ampliar a concepção de gestão democrática para além da eleição direta de diretor (a) pela comunidade escolar, em função do impedimento legal. O que também tem a ver com outros impedimentos na própria organização do Estado brasileiro, que não comporta processos democráticos fora do controle burocrático, do domínio da lógica dos técnicos em oposição à lógica dos cidadãos (NOGUEIRA, 2011). Abre-se, neste caso, uma disputa dramática para a reestruturação de leis educacionais no país, para que sejam reconhecidas as decisões que expressam a vontade legítima da comunidade escolar, mas que, em geral, são elaboradas fora da estrutura burocrática do Estado brasileiro.

Outro desafio é tornar o tema gestão democrática, e por extensão, a legislação educacional, temas a serem aprofundados no processo de formação inicial e continuada de educadoras e educadores nas instituições de ensino superior e em eventos educacionais e acadêmicos. Com isso, há maior possibilidade de ampliação das exigências desses 


\section{CIÊNCIAS HUMANAS}

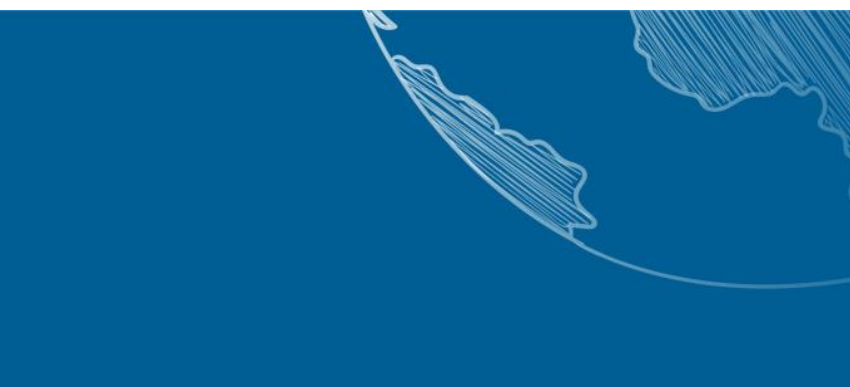

profissionais em relação aos seus direitos e firmar uma posição de sujeito na discussão, direcionamento e controle da política educacional municipal.

Esses desafios precisam ser enfrentados com a coerência ético-política necessária para assumir a denúncia contra a centralidade dos processos administrativos e a manipulação das pessoas, que tem excluindo a maioria da comunidade escolar dos debates municipais sobre a política educacional. Ou seja, o enfrentamento pode acontecer com a utilização do diálogo freireano como um instrumento de mediação entre pessoas, numa relação horizontal, para discutir as possibilidades, ao mesmo tempo em que seja discutida a ideologia gerencialista que pode ser sintetizada em uma máxima recorrente nos meios de comunicação e criticada por Paulo Freire: deve haver menos conversa $e$ mais resultados (FREIRE, 2000). Ou seja, menos diálogo, menos problematização e participação das pessoas nos processos decisórios e mais autoritarismo e centralização na política educacional.

Com relação às possibilidades da gestão democrática educacional, há que se reconhecer que não há impedimento legal efetivo para a implementação de relações democráticas no interior da escola e no sistema de ensino como um todo. As institucionalidades e os procedimentos estão garantidos em Lei e indicados em regulamentos específicos nos próprios municípios. Entretanto, como aconteceu com as conferências municipais de educação no Estado de Santa Catarina, podem ser utilizados como "faz de conta" para evitar o debate e a reunião de proposições que não interessam aos governantes conservadores e reacionários. Dessa forma, também é necessário retomar o trabalho formativo inicial e continuado da comunidade escolar como a aposta que o diálogo para o convencimento ativo é a possibilidade mais plausível para que a gestão democrática seja realmente efetivada.

Enfim, o silêncio da maioria dos educadores e das educadoras é o ponto de partida para uma reflexão mais demorada e aprofundada sobre como desenvolver processos formativos que sejam capazes de promover o pensar certo, que os coloquem no movimento de construção coletiva do Projeto Democrático-Participativo para os sistemas de ensino e o próprio Estado brasileiro. A gestão democrática se efetiva não só pela 
possibilidade da escolha do diretor (a), mas, acima de tudo, pelas relações democráticas que se iniciam na relação professor-aluno no espaço da escola e se desdobram nas institucionalidades e na adoção de procedimentos no interior delas e na gestão do sistema de ensino, com a participação direta da comunidade escolar para tomar as decisões necessárias na conquista da qualidade social da educação.

\section{REFERÊNCIAS}

BRASIL. Constituição de 1988. Constituição da República Federativa do Brasil: promulgação em 5 de outubro de 1988. Brasília: Senado Federal, 2014. Disponível em: <http://www.planalto.gov.br/ccivil03/constituicao/constituicao.htm>. Acesso em: 23 fev. 2014.

BRASIL. Lei $n^{\circ}$. 10.172, de 9 de janeiro de 2001. Aprova o Plano Nacional de Educação e dá outras providências. Diário Oficial [da] República Federativa do Brasil, Brasília, DF, 10 jan. 2001, p. 1. Disponível em: <http://www.planalto.gov.br/ ccivil_03/leis/leis_2001/110172.htm>. Acesso em: 15 dez. 2013.

BRASIL. LDB: Lei de diretrizes e bases da educação nacional [recurso eletrônico]: Lei $n^{\circ}$. 9.394, de 20 de dezembro de 1996, que estabelece as diretrizes e bases da educação nacional. 9. ed. Brasília: Câmara dos Deputados, Edições Câmara, 2018a Disponível em: http://www.planalto.gov.br/ccivil_03/LEIS/L9394.htmAcesso em: 23 Set. 2018.

BRASIL. Lei no ${ }^{\circ}$ 13.005, de 25 de junho de 2014. Diário Oficial [da] República Federativa do Brasil, Brasília, DF, 26 jun. 2018b, Edição Extra, p. 1. Disponível em: http://www.planalto. gov.br/ccivil 03/ Ato2011-2014/2014/Lei/L13005.htm. Acesso em: 20 Set. 2018.

FREIRE, Paulo. Pedagogia do Oprimido. 17. ed. Rio de janeiro: Paz e Terra, 1987.

FREIRE, Paulo. Pedagogia da Esperança. Rio de Janeiro: Paz e terra, 1994.

FREIRE, Paulo. Educação pela cidade. Rio de Janeiro: Paz e Terra, 1991.

FREIRE, Paulo. Pedagogia da Indignação - cartas pedagógicas e outros escritos. São Paulo: Editora UNESP, 2000.

GUARESCHI, Pedrinho. Empoderamento. Dicionário Paulo Freire. Danilo Streck; Euclides Redin; Jaime José Zitkoski (Orgs.). Belo Horizonte/MG: Autêntica, 2008, p. 165-166. 
KOSIK, Karel. Dialética do concreto. 3. ed. Rio de Janeiro/RJ: Paz e Terra, 1985.

LIMA, Licínio C. Organização escolar e democracia radical - Paulo Freire e a governação democrática da escola pública. 4. ed. São Paulo: Cortez Editora, 2009.

MOREIRA, Carlos Eduardo. Globalização das políticas públicas de educação básica no Governo Lula: uma metodologia para a democracia participativa em municípios brasileiros. 2016. Tese (Doutorado) - Pontifícia Universidade Católica.

MOREIRA, Carlos Eduardo. Pedagogia da ação política - a construção democrática da educação pública municipal. Florianópolis/SC: Insular, 2018.

NOGUEIRA, Marco Aurélio. Um Estado para a sociedade civil: temas éticos e políticos da gestão democrática. 3. ed. São Paulo: Editora Cortez, 2011.

SANTOS, Boaventura de Sousa. Democracia e Participação - o caso do orçamento participativo de Porto Alegre. Porto Alegre/RS: Afrontamentos, 2002. 